\title{
Two case of body packing of gold in Sri Lanka
}

\section{Introduction}

Smuggling is the secret movement of goods across national borders to avoid customs duties or import/export restrictions. Smuggling typically occurs when there is a higher demand for the particular goods or when the smugglers can make a large profit by avoiding custom duties. Drugs and weapons are the commonest material smuggle across the borders worldwide. In recent past it was reported that gold has been smuggled to India via Sri Lanka using various medias. The evaluation of it is the body pacing of gold. There were no reported cases of body packing of gold in indexed medical literature. There we present two cases of body packing of gold in Sri Lanka.

\section{Case I}

An Indian national was arrested by Sri Lankan custom officers at Bandaranaike air port, suspecting gold smuggling. His body was examined by the custom officers but could not find the concealed gold in his cloths and belongings. But still the scanners indicate that he conceal metal objects. The custom officers produced the suspect to on call judicial medical officer of district general hospital Negombo for further examination. On presentation, the examinee was looked excited. He was conscious and rational. Heart rates was slightly elevated, 92 beats per minute. Abdominal examination was unremarkable. The rectum was full of stools on digital rectal examination. Cardiovascular and respiratory system examination was unremarkable. A plain abdominal radiograph showed 10 pieces of metallic foreign bodies in abdomen in hypochondriac region (Figure 1). The patient admitted that he swallowed 10 pieces of gold about an hour before the departure. The patient was admitted to the casualty surgical unit for observation and he was given Lactulose and Bisacodyl (dulcolax) oraly and Bisacodyl suppository. During the hospital stay under the observation of custom officers and medical staff the examinee passed total of 10 capsule shape metallic foreign bodies of $2.5 \mathrm{~cm}$ long and $1 \mathrm{~cm}$ diameter (Figure 2) in three consecutive days. They were covered with a blue colour carbon paper and wrapped with a latex cover. The abdominal radiographs were taken each day and final abdominal radiograph did not demonstrate foreign bodies. He was discharged from ward to the custom officers and passed material was handed over to custom officers after sealed in front of the suspect.

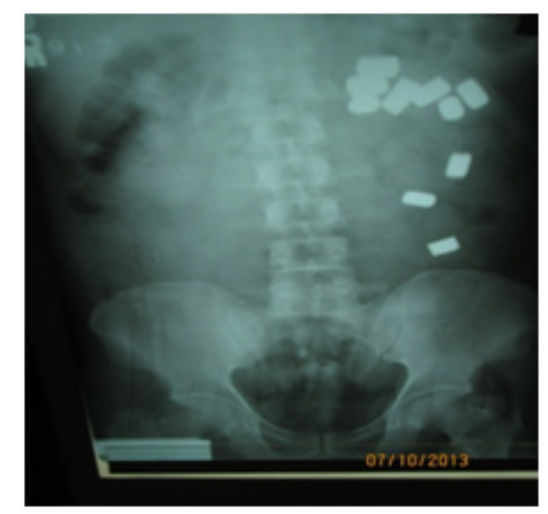

Figure I 10 metallic type foreign bodies in plain abdominal radiograph (on admission).

\author{
Volume 4 Issue I - 2017
}

\author{
Malintha de Silva \\ Department of Forensic Medicine, University of Kalaniya, Sri \\ Lanka
}

Correspondence: Malintha de Silva, Department of Forensic Medicine, Faculty of Medicine, University of Kalaniya, Ragama, Sri Lanka,Email malinthadesilva@yahoo.com

Received: December 0I, 2016 | Published: January 27, 2017

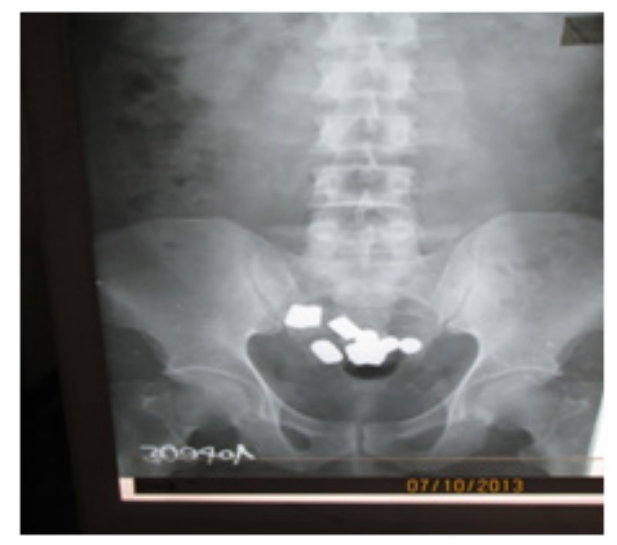

Figure 210 metallic type foreign bodies in plain abdominal radiograph (one day later with laxatives).

\section{Case 2}

A Sri Lankan 62 year old female was arrested by Sri Lankan custom officers at Bandaranayakaair port, suspecting gold smuggling (Figure 3). The custom officers produced the suspect to on call judicial medical officer of district general hospital Negombo for further examination. On the presentation, the examinee was looked normal. Cardiovascular, respiratory system examination and abdominal examination were unremarkable. On digital rectal examination anal sphincter tone was reduced. A metallic object was felt inside the rectum. A plain abdominal radiograph showed a piece of metallic foreign bodies in pelvic region (Figure 4). The patient denied that she had inserted anything inside the rectum. The patient was admitted to the casualty surgical unit and manually removed the foreign body from the rectum. It was a rectangular metallic cube of $4.5 \mathrm{~cm} \mathrm{X} 2.5 \mathrm{~cm} \mathrm{X} 1.5 \mathrm{~cm}$ in dimension (Figure 5) and it was covered with a black coloure carbon paper and wrapped with a latex condom. The abdominal radiograph was taken after the procedure and did not demonstrate foreign bodies. She was discharged from ward to the custom officers and passed material was handed over to custom officers after sealed in front of the suspect. 


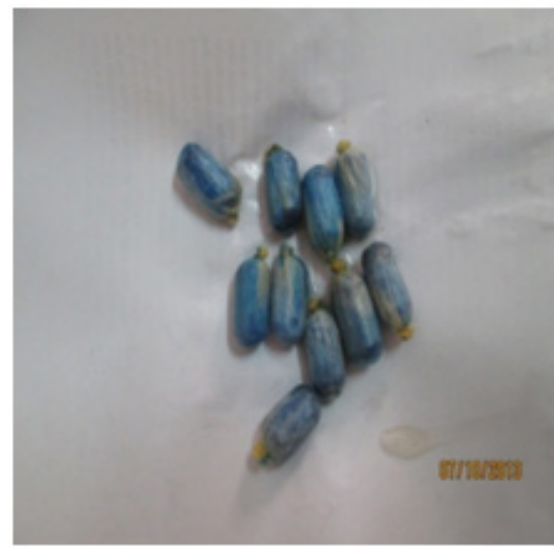

Figure 3 Capsule shaped gold pieces wrapped in latex cover.

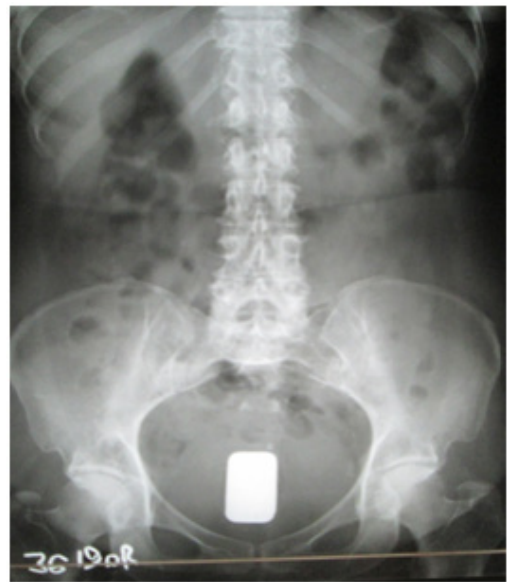

Figure 410 metallic type foreign bodies in plain abdominal radiograph (on admission).

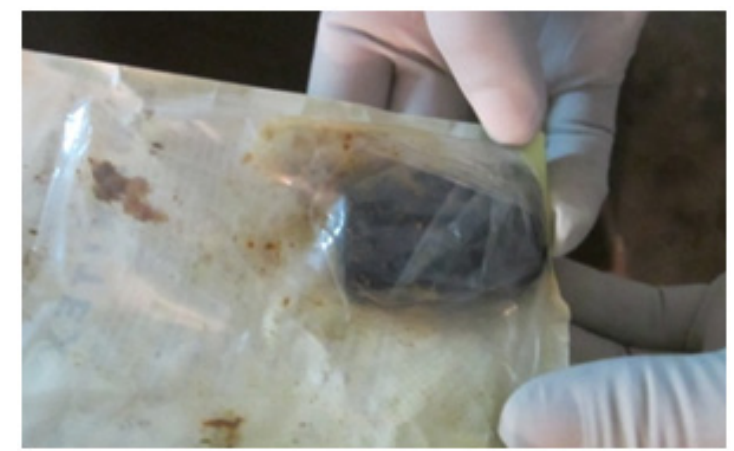

Figure 5Rectangular god cube covered with a black coloure carbon paper and wrapped with a latex condom.

\section{Discussion}

Body packing is a recognized mean of smuggling drugs worldwide. ${ }^{1-13}$ First reported case of body packing of drugs in medical literature was reported in 1973, a case of swallowing Hashish packed in condoms. ${ }^{2}$ So far there is no reported case of gold smuggling as body packing. There are three type of body packing. First, the "swallowers" who intentionally swallow large amount of transporting material before cross the international boundaries. ${ }^{3}$ Second type, the "pushers" use their rectum or the vagina to transport smuggling material. ${ }^{4,5}$ Third type, the "stuffers" swallow small amounts of transporting material because of fear of arrest at the time of crossing the boundaries. ${ }^{3}$ The swallowers frequently use anti-motility agents, such as diphenoxylate or loperamide to increase intestinal transient time, after swallowing the transporting material. After entering the country of destination, body packers use laxatives, cathartics, or enemas to help passage of their cargo rectally. ${ }^{3,6}$ On the other hand the pushers use laxatives or enemas to empty the rectum before pack the transporting media in the rectum. The smugglers frequently pack the material in capsule shape packs. ${ }^{1,3,6,11,12}$ The packets are made out of various materials, the most common is latex condoms which are easily available and can be swallowed or inserted into the rectum or the vagina easily. Other materials use for packing are finger of latex gloves, plastic bags, aluminum and balloon. ${ }^{14,15}$ In the both cases which presented here, the gold pieces were wrapped in carbon papers and then capsulated with latex condoms. There are three types of presentations of body packers including medical examination after detention or arrest by law -enforcement officers, acute symptoms of drug toxicity and bowel obstruction, asymptomatic body packers. ${ }^{1,2,6-8,14}$ A detailed history should be obtained to uncover the secrets of body packing. ${ }^{1,3}$ However they are poor historians and unreliable. ${ }^{1,3}$ In some cases, may be unable to provide a history owing to drug-induced toxic effects. ${ }^{6-8}$ Physical examination should include mental status, vital signs, size of the pupil, bowel motion, dermatological findings and rectal examination and vaginal examination. Physicians should be familiar with different clinical manifestations of drug toxicity. Opioid toxicity presents with a depressed level of consciousness. Opiate toxicity should be suspected when the clinical triad of pupillary miosis, central nervous system (CNS) depression and respiratory depression is present. Cocaine overdose causes euphoria, anxiety, behavioral change, acute toxic psychosis, muscle rigidity, mydriasis, fever, diaphoresis, tachycardia and hypertension followed by seizures and cardiovascular collapse. ${ }^{3,12,16}$ Gold is an innate substance and does not give rise to toxic effects but they can be give rise to bowel obstruction.

In the investigation of suspected body-packers, the plain abdominal and chest X-rays are good screening method help identify the majority of concealed packages and which cost less and freely available. Several imaging findings on abdominal x-ray are indicative of body packing, such as multiple radio-dense foreign bodies or "double-condom" sign. ${ }^{1,3,10,11}$ in which a crescent of air trapped between the different layers of latex makes them visible. The gold and metallic objects give a radio opaque shadow on the $\mathrm{X}$ - ray. However with the development of modern packing techniques and usage of sophisticated packing material by the smugglers, it increases the false negative rate of radiograph. ${ }^{3}$ In the above case two case the smugglers covered the gold was with carbon the papers which gives a poor image in the X-ray scanners used to screen passengers at the air port and helped to bypass them. Management decisions depend on the findings, type of material transporting, the location of packets within the gastrointestinal tract, and type and size of packets. Commonly the material can be evacuated with non invasive methods. Uncommonly, may need surgical interventions in cases of intestinal obstruction with the packs. ${ }^{2,13}$ In some occasions the body packers may develop toxic effects due to leaking of the packets and they need emergency medical management of toxicity. ${ }^{6-9,14}$ The above two cases of gold body packing were manage noninvasively, but there is a risk of intestinal obstruction due to their hard consistency and size. The long term effect of using of rectum to transport large size of gold pieces has not been reported. 


\section{Conclusion}

We reported two cases who used two different mode to transport gold as body packing. The described patients were managed noninvasively with supportive care. Body packing of gold was not reported earlier. Diagnosis of body packing is extremely difficult. Studying of body language is the key in detecting body packers.

\section{Acknowledgments}

None.

\section{Conflicts of interest}

None.

\section{References}

1. Soriano Perez MJ, Serrano Carrillo JL, Marin Montin I, et al. Hashish Body Packing: A Case Report. Case Rep Med. 2009;712573.

2. Deitel M, Syed AK. Intestinal obstruction by an unusual foreign body. Can Med Assoc J. 1973;109(3):211-212.

3. Makhtoom Shahnazi, Morteza Sanei Taheri, Ramin Pourghorban. Body Packing and Its Radiologic Manifestations: A Review Article. Iran J Radiol. 2011;8(4):205-210.

4. Benjamin F, Guillaume AJ, Chao LP, et al. Vaginal smuggling of illicit drug: a case requiring obstetric forceps for removal of the drug container. Am J Obstet Gynecol. 1994;171(5):1385-1387.

5. Sundkvist T, Johansson B, Widell A. Rectum carried drugs may spread hepatitis A among drug addicts. Scand J Infect Dis. 1985;17(1):1-4.
6. Wetli CV, Mittlemann RE. The "body packer syndrome" toxicity following ingestion of illicit drugs packaged for transportation. J Forensic Sci. 1981;26(3):492-500.

7. Gill JR, Graham SM. Ten years of "body packers" in New York City: 50 deaths. Journal of Forensic Sciences. 2002;47(4):843-846.

8. Bulstrode N, Banks F, Shrotria S. The outcome of drugs smuggling by 'body packers' the British experience. Ann $R$ Coll Surg Engl. 2002;84(1):35-38.

9. Wong GCK, Lai KK, Chung $\mathrm{CH}$. Management of body packers in the emergency department. Hong Kong Journal of Emergency Medicine. 2005;12(2):112-118.

10. Hierholzer J, Cordes M, Tantow H, et al. Drug smuggling by ingested cocaine-filled packages: conventional X-ray and ultrasound. Abdom Imaging. 1995;20(4):333-339.

11. Hergan K, Kofler K, Oser W. Drug smuggling by body packing: what radiologists should know about it. Eur Radiol. 2004;14(4):736-742.

12. Traub SJ, Hoffman RS, Nelson LS. Body packing-the internal concealment of illicit drugs. N Engl J Med. 2003;349(26):2519-2526.

13. Robinson T, Birrer R, Mandava N, et al. Body smuggling of illicit drugs: two cases requiring surgical intervention. Surgery. 1993;113(6):709-711.

14. Chakrabarty A, Hydros S, Puliyel JM. Smuggling contraband drugs using paediatric "body packers". Arch Dis Child. 2006;91(1):51.

15. Low VHS, Killius JS. Animal, vegetable, or mineral: A collection of abdominal and alimentary foreign bodies. Esophagus. 2000;4:6-8.

16. Ramrakha PS, Barton I. Drug smuggler's delirium. BMJ 1993;306(6883):1002. 